\title{
Thin and Rectangular Die Bond Pick-Up Mechanism to Reduce Cracking During the Integrated Circuit Assembly Process
}

\author{
Ahmad R.A. Rahman', Nazrul Anuar Nayan ${ }^{1 *}$ \\ 1 Department of Electrical Electronic and Systems Engineering, Faculty of Engineering and Built Environment, \\ Universiti Kebangsaan Malaysia, 43600 UKM Bangi, Selangor, Malaysia \\ * Corresponding author's e-mail: nazrul@ukm.edu.my
}

\begin{abstract}
The demand for small, thin, and lightweight electronic devices is increasing. More advanced design and assembly processes of electronic packaging technology have developed to fulfill this need. The critical processes in semiconductor packaging involved in meeting the ever increasing demands of technology include wafer back grinding, dicing, and die attachment. With low die thickness, the risk of die failure, which can cause functional damage, is high. In the die attachment process, the pin ejector causes an impact during the pick and place process. Those effects can result in a micro indentation or micro crack under the die and would be the weak point throughout the entire process. This study designed and evaluated an ejector system for the die attachment process. The proposed method uses a static pole heated inside the cavity for the platform to die before being ejected. Vacuum stabilizes the die suction. Moreover, heat softens the sawing tape and weakens the die adhesion. For die selection during the die attachment process, the results show that the critical die crack problem for a thin and rectangular die is solved using the proposed method. In summary, the packaging of semiconductors has advanced to accommodate the pick-up technology solution in relation to the challenging material needed for the current miniaturization market trend and demand.
\end{abstract}

Keywords. die attachment; miniaturization, integrated circuit; packaging process.

\section{INTRODUCTION}

Die attachment is one of the most critical integrated circuit (IC) packaging processes. Over the last few years, low die thickness which reduces drain-source on resistance, RDS(on), lower silicon resistance between top metal and paddle, improved heat dissipation, decreased stacked up package thickness, and reduced weight, has received higher demand. This three-dimensional technology represents the next wave of packaging innovation and will observe sharp growth in the years to come (Ibrahim et al. 2007). The trends represent a considerable challenge to the existing electronic packaging technology, mainly the die pick-up process. This process of handling thinner dies must be given extra attention to ensure the reliability and quality of semiconductor products (Huiqiang et al. 2015; Carine et al. 2014).
The situation is in fact worsening in recent years as the dies become increasingly thinner (Sing et al. 2014). At the back grinding process, the finished wafer thickness varies according to the set of dry polishing parameters used and such differences in the finished thickness would significantly impact die strength, especially for the $75 \mu \mathrm{m}$ wafer (Sun et al. 2007). As the IC chip becomes thinner, chip cracking between the adhesive tape and ultrathin IC chip increases due to the low strength of the chip in the die pick-up process (Eun-Beom et al. 2016).

Semiconductor dies normally range between 0.5 and $6.0 \mathrm{~mm}$ in size. The high aspect ratio is defined when a considerable difference exists between the width and length of a die; in other words, in the case of rectangular dies. This kind of die shape causes challenges to the die attachment process because of the uneven stresses of the thin 
die resulting in die warpage. Furthermore, the stress induced by the thermal mismatch of different materials may affect the assembly processes from die mounting, wire bonding, and molding to package singulation (Izhan et al. 2007). During the die attachment, dies are transferred from the sawing tape to the die paddle of a leadframe or substrate. The die pickup typically uses an ejector pin and rubber tip. The ejector pin pushes the die from the bottom and a collet assisted by the vacuum will pick it up, and then place the die on the paddle of the leadframe or substrate. All surfaces and structures of the die must be well protected during the die pick up process as their presence significantly increases the adhesion and contact angle between the dies and dicing tape (Carine et al. 2014). However, the aforementioned methodology does not work for thin dies with thickness of $75 \mu \mathrm{m}$ or lower. The ejector pin movements cause high impacts at the bottom of the die. These blows will then weaken the contact point and cause hairline cracks. This type of minimal cracks will develop into full cracks during the die attachment process. The cracks will worsen at subsequent processes such as during wire bonding, molding, lead trimming and forming, and electrical testing.

For low die thickness (50 to $75 \mu \mathrm{m}$ ) and a high aspect ratio die (i.e., when the length of the die is more than five times the width), die warpage due to imbalance stress is identified. Furthermore, the current ejection system produces a high impact to the back of die. Die hairline cracking will occur during the die attachment or subsequent processes. However, the hairline crack is not observable during the die attachment with the monitoring system and is normally detected during the electrical test. The failure test units will be decapsulated for the failure analysis. After decapsulation, further visual inspection will be conducted to ascertain the root cause of the die crack failure. In this case of a thin die, the standard die attachment process using an ejector needle may be unsuitable (Rahman et al. 2017).

In the typical die attachment process, the movement of the die pick up consists of a pushing force from the bottom and the pickup force from top. The pick-up process consists of two separate actions: peeling the foil from the chip and picking the chip from above with a vacuum tool (Meeding et al. 2004). During die pick-up, the change of the vacuum force will alter the die shape, especially during the vacuum release process (Zakaria et al. 2012). A suitable pick up tip or collet is employed to ensure that the die is flattened during picking and positioning. The design of the pickup tip which consists of a stopper was developed to straighten the warped die.

Several studies have attempted to minimize the movements during the die ejection from the sawing tape, the die pick-up from the bond head, and the die placement to the paddle leadframe. In the semiconductor industry, multiple thin die pick-up methods were developed to reduce the die stress and prevent die cracks (Qian and Liu, 2016). One of the techniques employed on the die-tape separation is the slider peel method. The slider peel scheme is suitable for the comparative pick-up of thin dies (Chuichi et al. 2010). However, this method has the disadvantage of slow output because of the unidirectional wafer table movement.

This paper presents an innovation for the ejection system. The pickup process handles die warpage by the pickup tip collet design. Static pillars, together with vacuum and the heat for the pickup, were used to eliminate the ejecting movements. In normal practice, the impact of an ejecting needle takes effect only in a limited area around the contact point and can boost local stress greatly by $8-10$ times, thereby resulting in local damage to chips as observed by a microscope (Bo Peng et al. 2011).

\section{Thin wafers}

The warpage observed with thin wafers would make the process more challenging compared to that for the non-warped counterpart. Figure 1 shows the warpage observed on a low thickness wafer.

In addition, the die curvature due to warpage on a thin wafer makes the situation even more problematic. Whenever high topography occurs on the die surface such as micro bumps, a copper pillar, and exposure Through Silicon Via (TSV), the situation worsens. Fabricating the holes remains the main difficulty in achieving high-performance device structure (Nur Dalila et al. 2016).

Figure 2 shows an example of a high aspect ratio die with the size of $32 \times 125$ mils. The challenge of a high aspect ratio die involves attaining consistent solder coverage with uniform placement in the $x$ and $y$ directions including the angular position. Low thickness increases complexity as die warpage will be created. 


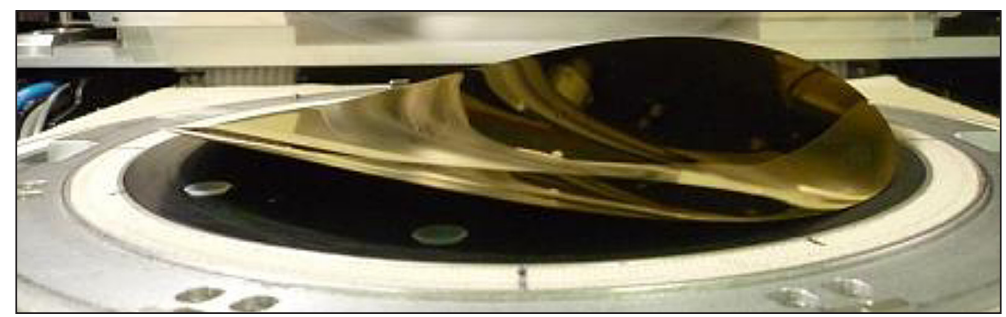

Fig. 1. Warpage observed on a low thickness wafer

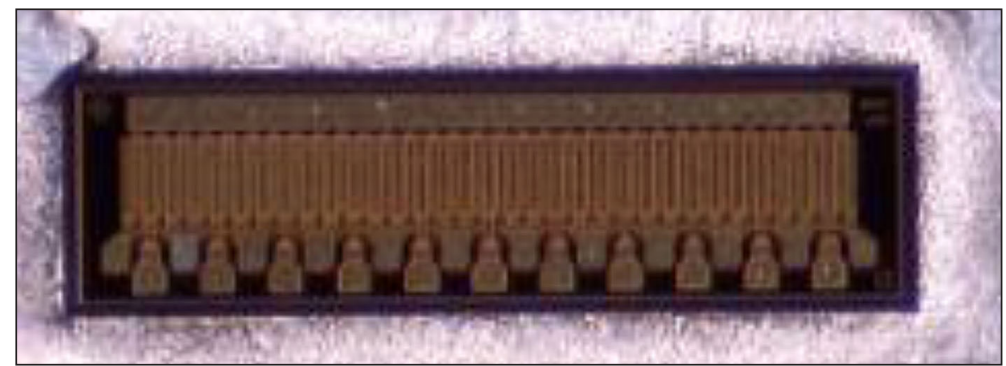

Fig. 2. High aspect ratio die of $32 \times 125$ mils

\section{IC failure issues}

Figure 3 shows an example of a hairline crack. The hairline crack indicates the discontinuation and breakage of circuits in the die. That cracking can lead to full cracks and contributes to device malfunction. However, some incidences of marginal hairline cracks occur and the devices may pass the outgoing test. On some occasions, infra-red (IR) reflow is performed after a postmold cure to expose the marginal hairline crack and the device is subsequently identified as unfit after testing.

Figure 4 shows the confocal scanning acoustic microscopy (CSAM) result of the delamination observed at the edge of die but does not illustrate the hairline crack across the die. The top of die seems clean and the hairline crack is likely not due to electrical over-stress (EOS) failure.

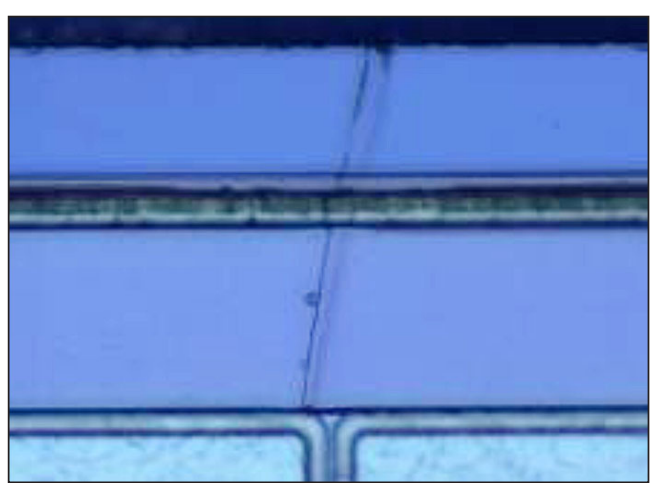

Fig. 3. Observed hairline crack
In Figure 5, the imprint of the mylar shows the impact from the ejector pin. The ejector pin has a rounded shape with a certain radius at the tip, but it can still be harmful for low thickness die. Such a die is not strong enough to sustain the impact from the ejector pin.

Thus, the process with an ejector pin is unsuitable for use with a thin die. Figure 6 shows the hairline crack observed at the side wall of the die. The line is not only scratched but cracked across the die. A scanning electron microscope (SEM) image of the wall of the die is shown in Figure 6. That line appears to be propagating into several crack lines. Thus, the device has a critical mechanical stress transmitted to other regions of the die.

Figure 7 shows the crack line from the bottom of the die that propagates to the top. The wavy formation of wavy lines of metal compression gives strong evidence that the crack direction comes from the bottom of the die. The crack location is

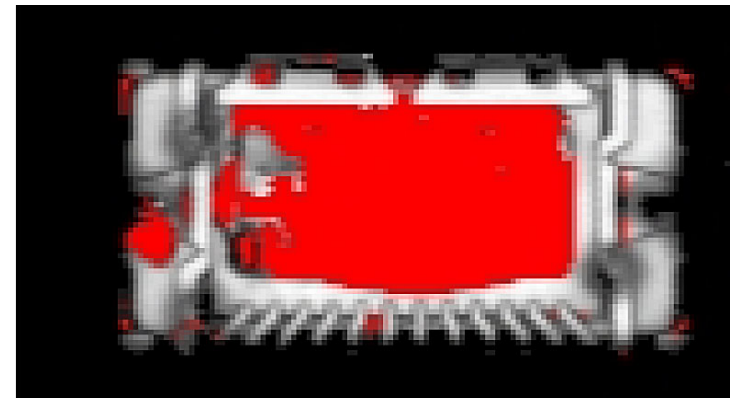

Fig. 4. CSAM image results 


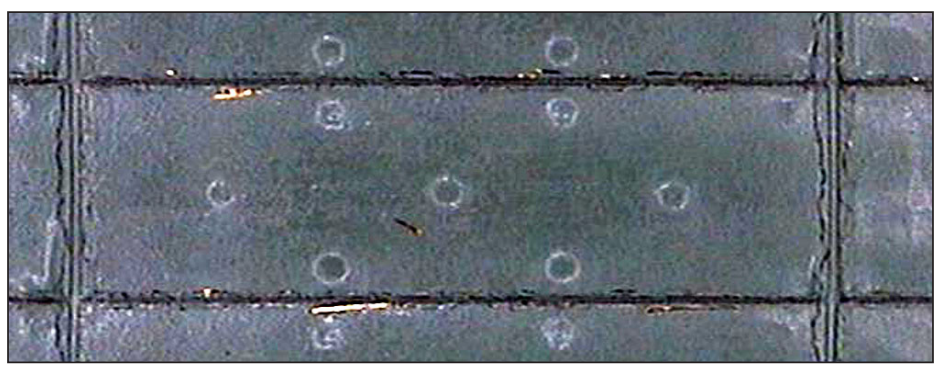

Fig. 5. Ejector pin imprint on the mylar tape

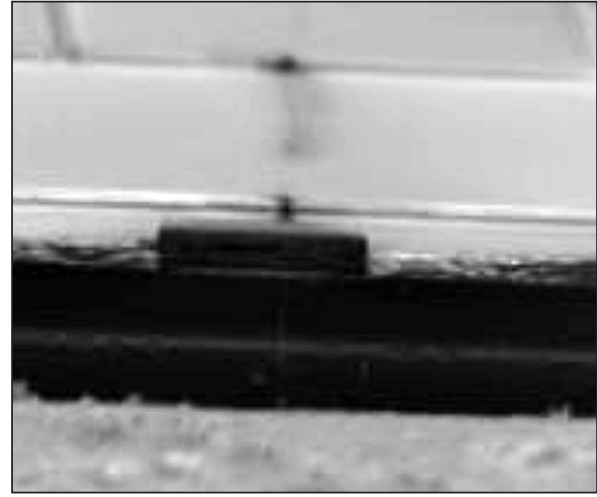

Fig 6. SEM image on side wall of die

aligned with the location one of the ejector pin. Thus, an improvement is required to perform the die pick-up without any issue. The evaluation of the die pickup conditions was performed earlier to observe the effect of the pick-up force and the needle size and height on the die crack and needle mark (Jalar et al. 2008).

Figures 8 and 9 show the levels of heatsink concavity after the die attachment and mold process by using finite element analysis. The die attachment was performed using a temperature of $380{ }^{\circ} \mathrm{C}$ for the solder wire melting. Figure 8 shows the higher concavity of the heatsink. The warpage of the molding process with a temperature of approximately $180{ }^{\circ} \mathrm{C}$ shows lower concavity of the leadframe. This outcome occurs because of the relationship of paddle concavity with the environment temperature. Therefore, a concavity of the die paddle occurs between die attachment and mold process. The difference will create stress to the die and cause the die to crack. However, the warpage of die paddle will exhibit a different level of concavity in other processes.

The die has less strength and will sustain stress due to the ejector needle, with the combination of other stresses due to heatsink warpage and mold lock bump, thereby making the die crack during or before molding. Local die cracking or scratch

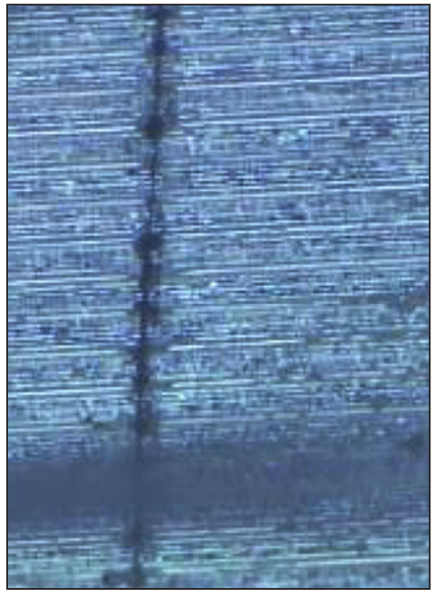

Fig 7. SEM image on fractured surface

marks on the backside are commonly observed in the microelectronics packaging industry and readily lead to failure in subsequent processes or practical services.

\section{METHODOLOGY}

Prior to the decapsulation, the unit which is suspected of having a die crack will undergo inspection of its outer physical conditions for any damage. The outcome will be confirmed with a non-destructive test such as X-ray and CSAM. Basically, failure arising from an external force or EOS failure will be ruled out. The investigation involved failure analysis to ascertain the root cause of the failure, which was also identified with SEM. A complete solution for a crack growth problem includes determination of the crack path (Arabi et al. 2017). As the hairline crack die is observable from the top of die, further investigation can be conducted through inspection on the crack surface. The die is separated into two pieces and the crack surface is examined. Warpage simulation was performed on the die attachment process of the soft solder, and the temperature inside the tunnel ranged between 360 and $380{ }^{\circ} \mathrm{C}$. The 


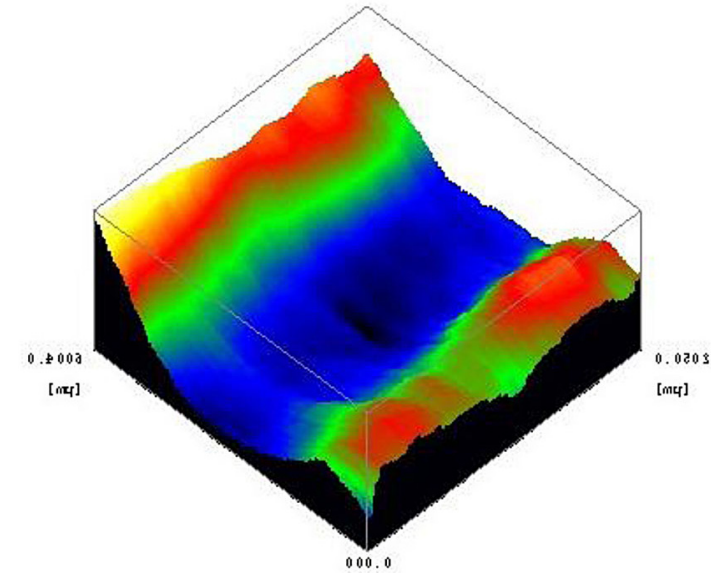

Fig. 8. High concavity of the heatsink after die attachment

solder needs to be wet before the die is placed on top of the die paddle. At those temperatures, the coefficient of thermal expansion occurs and causes paddle warpage.

The top of die ejector pepperpot uses a cavity for the die to rest whenever it is aligned for the die pick-up. Inside the cavity, several pillars are statically placed at the same level of the surface. Heat is applied and softens the mylar tape. The die and the tape will be aligned and the tape is pulled down and peeled off from the back of the die. The pillar is the only place where the mylar tape remains intact. However, this proposed method gives a minor force compared to the vacuum from the pick-up tip. The pillar is heated up by the round heater element mounter. The temperature is approximately $110^{\circ} \mathrm{C}$, thereby enabling the softening of the mylar. Sufficient time allocated during the pick-up entails approximately $1 \mathrm{sec}$ for the mylar to be pulled down and separated from the bottom of die. The mounted round heater element is controlled by the temperature thermostat. The heat is set between $100{ }^{\circ} \mathrm{C}$ to $120^{\circ} \mathrm{C}$. Normally, the temperature will be set at 110 to $112^{\circ} \mathrm{C}$ and will be finetuned if any pick-up challenge is observed.

Once the die is released from the mylar tape, the pick-up process will take over by using the pick-up tip. The pick-up tip has a special feature of a stopper at the side of the vacuum hole to straighten the warped die before placement. This process will enhance the stability of the die placement without a die tilt issue and facilitate uniform bond line thickness (BLT). The BLT is crucial for providing a cushioning effect for the die from the package stress. IC chip device with high aspect ratio of $32 \times 125$ mils,

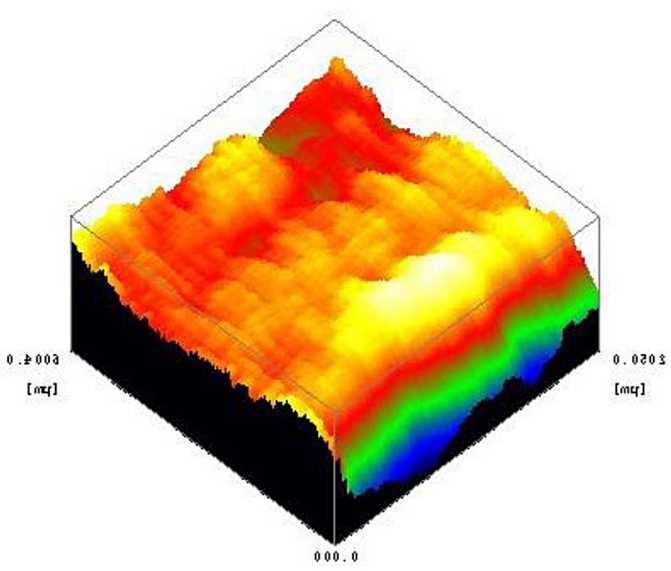

Fig. 9. Low concavity of heatsink after molding

75 um thickness which would have a higher risk of crack die if using ejector needle has been used for this study.

The ejectorless system is built using an ejector cavity with several pillars with zigzag alignment. The zigzag alignment serves to avoid the cantilever effect which may break the die. A vacuum suction holds down the die. Heat is supplied to reduce the adhesion of the sawing tape to allow for easy peeling off from the back of the die.

\section{RESULTS AND DISCUSSION}

The ejectorless pick-up is employed to overcome the issue of die cracking for the die attachment process. The design of the ejectorless pick-up seeks to eliminate the usage of the standard ejector pin which is unsuitable with thin dies.

Figure 10 shows the top of the ejectorless pepperpot, which supports the die during pickup. The contact points to the die are distributed to the pillars which have a large diameter for the ejector pin and corner rib support. No movement impact occurs from the bottom of the die because the pillars are under static conditions.

Figure 11 shows the die on the mylar as positioned on the ejectorless pepperpot during the die pick up process. First, the high aspect ratio die is aligned to the cavity. Next, the vacuum is applied and the heat from the pillars and corner ribs surface softens the mylar before pick-up.

Figure 12 shows the internal mechanical parts of the ejectorless pepperpot with a heater 


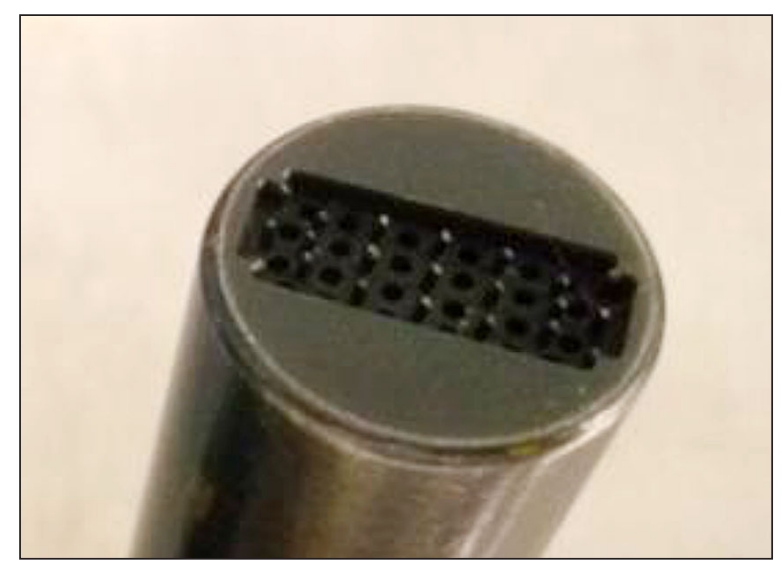

Fig. 10. Ejectorless cavity

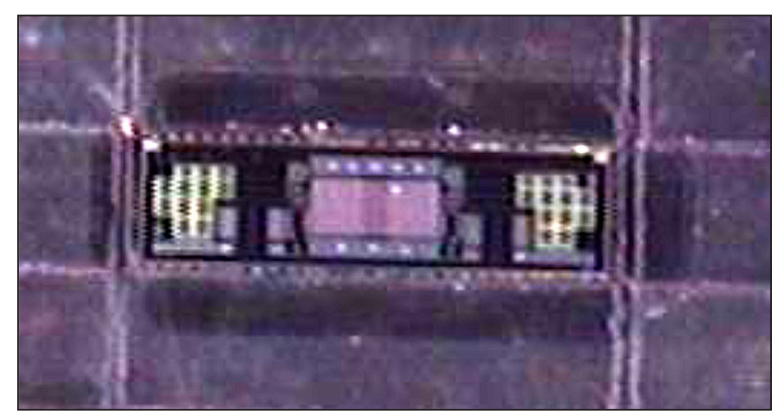

Fig. 11. Die position on ejectorless pepperpot

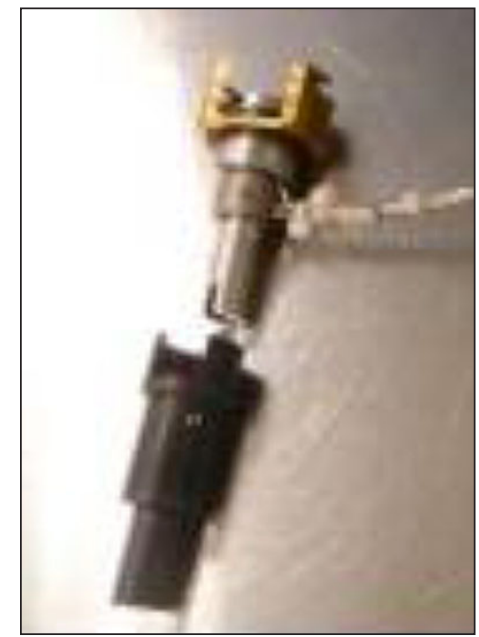

Fig. 12. Round heater element mounter

element mounter to heat up the top ejector cavity with a temperature of approximately $100{ }^{\circ} \mathrm{C}$ to soften the mylar tape before die pick up. The assembly was designed with consideration of low change over time between the standard and ejectorless pickup.

Figure 13 shows a top view of the ejectorless pepperpot. A smaller top portion enables die pick up at the side of the wafer from the grip ring. Ensuring that the entire die on the wafer can be accessed by the ejectorless pepperpot is crucial. Normally, the die pick-up follows the wafer map position and the ejectorless pepperpot must be able to pick up any good die indicated in the wafer map.

Figure 14 shows the pick-up tip with a design for the warp stopper. The warp stopper ensures that the die position remains flat during the attachment process. This placement prevents any issue of die attach material voids which can lead to quality and reliability problems.

The die crack issues that occur whenever the typical ejector system is employed were solved by using the ejectorless pick up system. The system can resolve the problem of die cracking during the die attachment process or of weak die strength and the failure at the subsequent process. The improvement reached zero cracking issues. Table 1 shows the crack issue detected after decapsulation on the electrical test

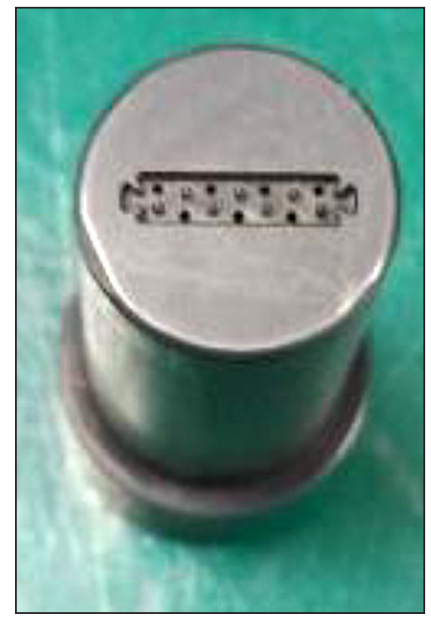

Fig. 13. Ejectorless pepperpot

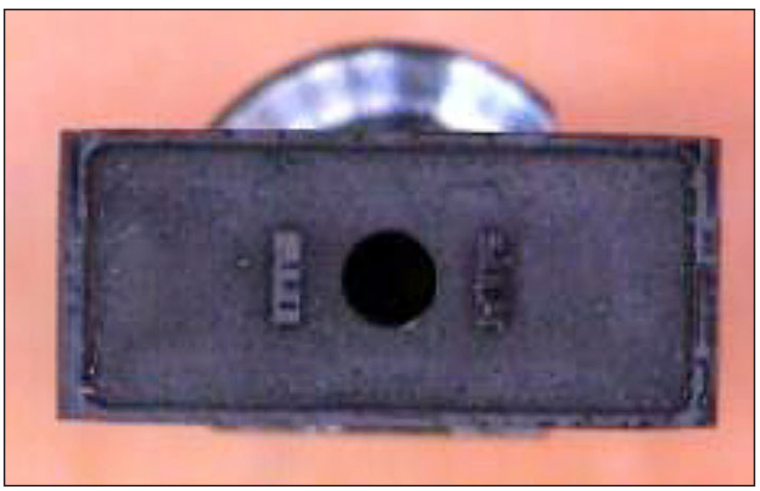

Fig. 14. Pick-up tip with warp stopper 
Table 1. Test and decapsulation results before the optimization

\begin{tabular}{|c|c|c|}
\hline No. & DC yield $(\%)$ & Decapsulation results (crack die) \\
\hline 1 & 96.88 & $4 / 5$ \\
\hline 2 & 95.77 & $5 / 5$ \\
\hline 3 & 91.27 & $5 / 5$ \\
\hline 4 & 94.50 & $3 / 5$ \\
\hline 5 & 81.30 & $5 / 5$ \\
\hline
\end{tabular}

Table 2. Optimization test result post-TC500 after the optimization

\begin{tabular}{|c|c|c|c|c|}
\hline No. & In & Out & Yield (\%) & Decapsulation results (crack die) \\
\hline Qual 1 & 50 & 50 & 100 & $0 / 5$ \\
\hline Qual 2 & 50 & 50 & 100 & $0 / 5$ \\
\hline Qual 3 & 50 & 50 & 100 & $0 / 5$ \\
\hline
\end{tabular}

failure of five production lots. Table 2 presents the result of $100 \%$ yield of electrical test after the temperature cycle test, TC500. No die cracks were observed after decapsulation on three qualification lots.

\section{CONCLUSION}

The demand for small, thin, and lightweight electronic devices is increasing. The proposed method offers a long-awaited solution of the die pick-up method required for solving the die cracking issue for an ultra-thin die. However, the process takes a longer time than that for the normal ejector pin usage, and this feature may lead to slower output (units per hour). The shortcomings of the suggested method do not present a major problem given the importance of the solutions for the die cracking with ultra-thin, high aspect ratio die.

\section{REFERENCES}

1. Abdullah Z., Vigneswaran L., Ang A. \& Yuan G.Z. 2012. Die attach capability on ultra-thin wafer thickness for power semiconductor. 35th IEEE/ CPMT International Electronics Manufacturing Technology Conference (IEMT), 1-5.

2. Arabi F., Theolier L., Youssef T., Medina M., Deletage J.-Y. \& Woirgard E. 2017. Effect of voids on crack propagation in AuSn die attach for hightemperature power modules. 18th International Conference on Thermal, Mechanical and MultiPhysics Simulation and Experiments in Microelectronics and Microsystems (EuroSimE), 1-6.

3. Peng B., Huang Y.A., Yin Z.P. \& Xiong Y.L. 2011.
On the analysis of dynamic effect in the die pickup process. 12th International Conference on Electronic Packaging Technology and High Density Packaging, 1-4.

4. Jeon E.B., Park S.H., Yoo Y.S. \& Kim H.S. 2016. Analysis of interfacial peeling of an ultrathin silicon wafer chip in a pick-up process using an air blowing method. IEEE Transactions on Components, Packaging and Manufacturing Technology, 1696-1702.

5. Qian R. \& Liu Y. 2016. Thin and large die assembly pick up process optimization by dynamic modeling. 17th International Conference on Electronic Packaging Technology (ICEPT), 147-152.

6. Shen H., L. Ye, Tang L. \& Liu Z. 2015. Study on thin die pick-up process based on Taguchi method. 16th International Conference on Electronic Packaging Technology (ICEPT), 1344-1347.

7. Miyazaki C., Shimamoto H., Uematsu T., Abe Y., Kitaichi K., Morifuji T. \& Yasunaga S. 2010. Development of high accuracy wafer thinning and pickup technology for thin wafer(die). IEEE CPMT Symposium Japan, 1-4.

8. Liau W.S. \& Gan T.K. 2018. Collet Auto Clean System. A smart automatic solution for die bonding pick up tool lifespan \& throughput enhancement. IEEE 38th International Electronics Manufacturing Technology Conference (IEMT), 1-6.

9. Medding J., Stalder R., Niederhauser M. \& Stoessel P. 2004. Thin die bonding techniques. IEEE/ CPMT/SEMI 29th International Electronics Manufacturing Technology Symposium, 68-73.

10. Gerets C., Derakhshandeh J., Wang T., Capuz G., Podpod A., Demeurisse C., Rebibis K.J., Miller A., Beyer G. \& Beyne E. 2014. Picking large thinned dies with high topography on both sides. IEEE 16th Electronics Packaging Technology Conference (EPTC), 175-179.

11. Chan Y.S., Chew J., Goh C.H., Chua S.K. \& Yeo A. 2014. Characterization of dicing tape adhesion for 
ultrathin die pick-up process. IEEE 16th Electronics Packaging Technology Conference (EPTC), 554-557.

12. Sun W., Zhu W.H., Che F.X., Wang C.K., Sun A.Y.S. \& Tan H.B. 2007. Ultra-thin die characterization for stack-die packaging. Proceedings 57th Electronic Components and Technology Conference, 1390-1396.

13. Ahmad I., Bachok N.N., Chiang N.C., Talib M.Z.M., Rosle M.F., Latip F.L.A., Aziz Z.A. 2007. Evaluation of different die attach film and epoxy pastes for stacked die QFN package. 9th Electronics Packaging Technology Conference (EPTC), 869-873.

14. Abdullah I., Chiang N.C., Mokhtar U., Said A., Talib M.Z., Ahmad I. 2007. Warpage and wire sweep analysis of QFN molded strip using experimental and modeling methods. 9th Electronics Packaging Technology Conference, EPTC, 494-498.

15. Jalar A., Rosle M.F., Hamid M.A.A. 2008. Die attach film performance in 3D QFN stacked die. WSEAS Transactions on Applied and Theoretical Mechanics, 3(3), 104-113.

16. Rahman A.R.A., Nayan N.A. 2019. Critical challenges and solutions for device miniaturization in integrated circuit packaging technology. Journal of Engineering and Applied Sciences, 13(15), 6025-6032.

17. Zamani N.D.M., Zain A.R.M., Majlis B.Y. 2016. Modelling of 2-D Gallium Nitride (GaN) photonic crystal. 2016. 12th IEEE Int. Conf. on Semiconductor Electronics (ICSE 2016), 54-56.

18. Hou L., Tan S., Yang L, Zhang Z., Bergmann N.W. 2017. Autonomous wireless sensor node with thermal energy harvesting for temperature monitoring of industrial devices. International Journal of Online and Biomedical Engineering (iJOE), 13(4), 75-82.

19. Yu X.W. 2017. Design and application of wireless sensor network monitoring software based on LABVIEW. International Journal of Online and Biomedical Engineering (iJOE), 13(5), 29-42.

20. Khoo V.C. 2019. A case study of return on investment for multisites test handler in the semiconductor industry through theory of industry $4.0 \mathrm{ROI}$ Relativity. International Journal of Recent Contributions from Engineering, Science \& IT (iJES), 7(3), 23-40. 